\title{
HPLC Comparison of Supercritical Fluid Extraction and Solvent Extraction of Coumarins from the Peel of Citrus maxima Fruit
}

\author{
Wen-Yuh Teng, ${ }^{1}$ Chien-Chih Chen ${ }^{2}$ and Ren-Shih Chung ${ }^{1 *}$ \\ ${ }^{1}$ Department of Agricultural Chemistry, National Taiwan University, Taipei, Taiwan \\ ${ }^{2}$ National Research Institute of Chinese Medicine, Taipei, Taiwan
}

\begin{abstract}
The efficiency of carbon dioxide supercritical fluid extraction (SFE) of the biologically active compounds imperatorin, meranzin and meranzin hydrate from the fruit peel of Citrus maxima Merr. has been compared with that of solvent extraction with acetone. Under the best SFE conditions tested for the three coumarins, which involved extraction at $50^{\circ} \mathrm{C}$ and $27.6 \mathrm{MPa}$, the extractive efficiencies were 84,76 and $18 \%$ for imperatorin, meranzin and meranzin hydrate, respectively. The presence of modifiers significantly affected the extraction efficiency: the highest extraction efficiency of the three coumarins was obtained with ethanol as modifier. Copyright (c) 2005 John Wiley \& Sons, Ltd.
\end{abstract}

Keywords: Supercritical fluid extraction; modifiers; HPLC; imperatorin; meranzin; meranzin hydrate; Citrus maxima.

\section{INTRODUCTION}

Imperatorin $\{9-[(3-m e t h y l-2-b u t e n y l)-7 \mathrm{H}-f u r o[3,2-$ 9][1]benzopyran-7-one\} (1), meranzin [8-(3,3-dimethyloxiranylmethyl)-7-methoxy-chromen-2-one] (2) and meranzin hydrate [8-(2,3-dihydroxy-3-methyl-butyl)-7methoxy-chromen-2-one] (3) are coumarins isolated from the fruit peel of C. maxima (Rutaceae). Imperatorin exhibits a wide spectrum of biological effects (Yamahara et al., 1985; Averbeck, 1989; Kumar et al., 1994; Chen et al., 1996; Kwon et al., 1997; Chiou et al., 2001; Colombain et al., 2001; Liao, 2002), whilst 2 and 3 possess cytotoxic activities (Hitotsuyanagi et al., 1996).

Together with coumarins, the fruit peel of $C$. maxima is rich in essential oil, and the specific isolation of the active compounds from peel by $\mathrm{CC}$ is tedious and time-consuming. Supercritical fluid extraction with carbon dioxide $\left(\mathrm{SFE}-\mathrm{CO}_{2}\right)$ is an attractive alternative that offers several advantages, including speed of extraction, high mass transference, completeness of extraction, elimination of the analyte concentration step, cost savings, the absence of toxic solvent and simplicity of analysis (Williams, 1981; Brogle, 1982; Larson and King, 1986). The solvent strength of a supercritical fluid may be increased by increasing the density of SFE- $\mathrm{CO}_{2}$ with appropriate modifiers (Hills and Hill, 1993; Sanagi and Ahmed, 1993; Hanson, 1994; Ashraf-Khorassani et al., 1995).

The aim of the present study was: (a) to study the extraction efficiency of SFE- $\mathrm{CO}_{2}$ for compounds 1-3 in peel of C. maxima (shaddock), and (b) to develop a method for the simultaneous quantitative determination of the three coumarins by the HPLC.

\footnotetext{
* Correspondence to: Ren-Shih Chung, Department of Agricultural Chemistry, National Taiwan University, Taipei, Taiwan.
}

E-mail: chungrs@ntu.edu.tw

\section{EXPERIMENTAL}

Chemicals and reagents. Liquid $\mathrm{CO}_{2}$ (with helium head) was purchased from the Chin Fun Gas Company (Taipei, Taiwan). Ethanol was purchased from the Taiwan Tobacco and Liquor Corporation (Taipei, Taiwan), whilst HPLC-grade acetone, acetonitrile and $n$-hexane were from Merck (Darmstadt, Germany).

Preparation of samples and standards. Fruit peel of C. maxima (shaddock) was dried at $45^{\circ} \mathrm{C}$ to constant weight and pulverised. Dried peel $(2 \mathrm{~kg})$ was extracted by SFE- $\mathrm{CO}_{2}$ at $50^{\circ} \mathrm{C}$ and $27.6 \mathrm{MPa}$, and the extract (33.07 g) subjected to CC over silica gel. Successive elution with $n$-hexane:ethyl acetate mixtures (1:0, 15:1, 10:1, 5:1, 2:1, 1:1 and 0:1) gave 18 fractions. The fraction obtained with $n$-hexane:ethyl acetate at 10:1 was further subjected to $\mathrm{CC}$ over silica gel to yield $\mathbf{1}(1.43 \mathrm{~g}), \mathbf{2}(1.02 \mathrm{~g})$ and $\mathbf{3}(50 \mathrm{mg})$. The identities of these coumarins were confirmed by MS and NMR spectra, and their purities were determined as $>98 \%$ using the HPLC method.

SFE- $\mathrm{CO}_{2}$. Extractions were performed using a laboratoryconstructed apparatus: the deliver system of the modifier consisted of an HPLC pump. An extraction cartridge was filled with $100 \mathrm{~g}$ of powdered dried fruit peel and extraction was carried out with a continuous flow of $\mathrm{CO}_{2}$. Two temperature levels $\left(40\right.$ and $\left.50^{\circ} \mathrm{C}\right)$ combined with two pressure levels (27.6 and 34.5 MPa), yielding four treatments in all, were tested. Extraction was carried out for $0.5 \mathrm{~h}$ in static mode, following by $6 \mathrm{~h}$ in dynamic mode. The final extract was collected in a tube containing $50 \mathrm{~mL}$ of ethanol. In all extraction procedures, the $\mathrm{CO}_{2}$ flow rate was maintained at $1 \mathrm{~L} / \mathrm{min}$ and the restrictor heated was maintained at $65^{\circ} \mathrm{C}$.

For extractions in the presence of modifier, $50 \mathrm{~mL}$ of $n$-hexane, acetone or ethanol were pumped into the 
<smiles>CC(C)=CCOc1c2c(cc3ccc(=O)oc13)C=CC2</smiles>

Imperatorin (1)<smiles>COc1ccc2ccc(=O)oc2c1CC1OC1(C)C</smiles>

Meranzin (2)<smiles>COc1ccc2ccc(=O)oc2c1CC(O)C(C)(C)O</smiles>

Meranzin hydrate (3) extractive cartridge with the HPLC pump prior to static mode extraction. After $0.5 \mathrm{~h}$ of static extraction, the modifier was pumped into the $\mathrm{CO}_{2}$ line and the flow rate set at $0.5 \mathrm{~mL} / \mathrm{min}$ for $1 \mathrm{~h}$; the remaining $5 \mathrm{~h}$ of dynamic extraction were performed with $\mathrm{CO}_{2}$ alone as described above.

Conventional extraction. Powdered dried fruit peel (1 g) was extracted with acetone under reflux for $1 \mathrm{~h}$, after which the extract was filtrated and the extraction process repeated three times. Finally the concentrated extracts were combined.

Preparation of samples for the quantitative determination of coumarins. (a) The SFE- $\mathrm{CO}_{2}$ extract from dried fruit peel was dissolved in ethanol; (b) the residue $(1 \mathrm{~g})$ of dried fruit peel remaining after SFE-CO $\mathrm{C}_{2}$ extraction was extracted with acetone under reflux for $1 \mathrm{~h}$ and filtered; (c) the extract from the conventional extraction process was re-dissolved in acetone and diluted to $100 \mathrm{~mL}$ (as control).

An aliquot $(1 \mu \mathrm{L})$ of sample was added to the same volume of $1 \%$ naphthalene (internal standard) before being subjected to HPLC. The coumarin content was calculated by means of respective calibration curves.

HPLC analysis. A Hewlett-Packard/Agilent (Palo Alto, CA, USA) Module 1100 LC system, equipped with a degasser, a pump and a UV detector, linked to a Rheodyne (Cotati, CA, USA) injection valve with a $20 \mu \mathrm{L}$ sample loop was used in this study. Determinations were carried out using a Merck Chromolith ${ }^{\mathrm{TM}}$ RP-18e column $(100 \times 4.6 \mathrm{~mm}$ i.d. $)$ with a mobile phase consisting of acetonitrile (solvent $\mathrm{A}$ ) and water containing $1 \%(\mathrm{v} / \mathrm{v})$ acetic acid (solvent $\mathrm{B})$. The gradient program commenced at 20:80 (A:B) for $5 \mathrm{~min}$, followed by a linear gradient to $28: 72$ in $0.5 \mathrm{~min}$, maintained at $28: 72$ for $6.5 \mathrm{~min}$, followed by a linear gradient to $30: 70$ in $0.5 \mathrm{~min}$, maintained at 30:70 for $7.5 \mathrm{~min}$, followed by a linear gradient to $32: 68$ in $0.1 \mathrm{~min}$, and maintained at 32:68 for $40 \mathrm{~min}$. The flow rate was $2 \mathrm{~mL} / \mathrm{min}$, the injected volume was $20 \mu \mathrm{L}$, and the coumarins were detected at $315 \mathrm{~nm}$.

\section{RESULTS AND DISCUSSION}

\section{HPLC separation of coumarins}

The HPLC separation of imperatorin (1), meranzin (2), meranzin hydrate (3) and the internal standard naphthalene is shown in Fig. 1; the retention times of the respective analytes were $51.2,12.0,5.3$ and $33.8 \mathrm{~min}$.

\section{Calibration of quantitative method.}

The regression equations for the coumarins were as follows:

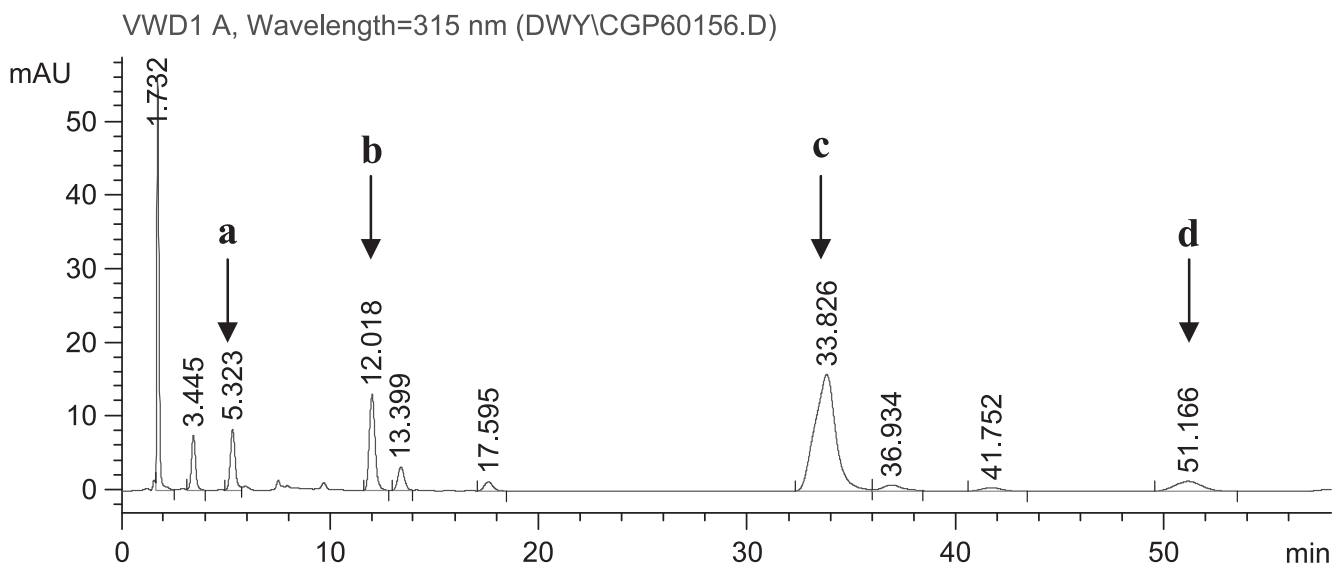

Figure 1. HPLC profile of an acetone extract of the fruit peel of Citrus maxima. Key to peak identity: a, meranzin hydrate (3); b, meranzin (2); c, naphthalene (internal standard); d, imperatorin (1). (For chromatographic protocol see the Experimental section.) 
- imperatorin (1) $-y=9.0846 x-0.0013$ (where $y$ is the ratio of the peak area of the coumarin to the internal standard and $x$ is the coumarin concentration); $r=$ $0.9989(n=4)$; concentration range $45-200 \mu \mathrm{g} / \mathrm{mL}$;

- $\operatorname{meranzin}(2)-y=8.6642 x-0.0295 ; r=0.9997(n=4)$; concentration range $45-270 \mu \mathrm{g} / \mathrm{mL}$;

- meranzin hydrate $(\mathbf{3})-y=8.1897 x+0.0212 ; r=1.0000$ $(n=4)$; concentration range $14-196 \mu \mathrm{g} / \mathrm{mL}$.

In each case there was a good linear relationship between the peak area elicited by HPLC and the concentration of analyte, as demonstrated by regression coefficients that were not significantly different from $1(p<0.05)$.

\section{Solvent extraction of coumarins}

The amounts of $\mathbf{1}, \mathbf{2}$ and $\mathbf{3}$ that could be extracted by acetone from the fruit peel of C. maxima were 1.34, 2.63 and $1.47 \mathrm{mg} / \mathrm{g}$, respectively.

\section{SFE extraction of coumarins}

The extraction efficiency was the highest when the extraction temperature was $50^{\circ} \mathrm{C}$ and the pressure was 27.6 MPa (Table 1). However, portions of the solutes remained in the extraction pathways or became plugged in the restrictor and lowered the extraction efficiency. $\mathrm{SFE}-\mathrm{CO}_{2}$ extraction was able completely to remove imperatorin from the fruit peel of $C$. maxima since $\mathbf{1}$ was not detected in the residues. In the case of $\mathbf{2}$, the amount retained in the residue following SFE extraction was lowest under the conditions $50^{\circ} \mathrm{C}$ and 27.6 MPa.

The solubility of coumarins in $\mathrm{CO}_{2}$ in the absence of modifier decreases as the polarity of the functional groups of the coumarins increases (Table 1). Choi et al. (1998) found that substitution of the functional group of a compound tended to reduce its solubility in the order methyl > methoxyl > hydroxyl. In the present study it was established that the extractive efficiency of SFE- $\mathrm{CO}_{2}$ with the addition of a modifier, which alters the polarity of the $\mathrm{CO}_{2}$, was higher than that determined in the absence of a modifier. The increase in extractive efficiency following the addition of ethanol was higher than with the other two modifiers tested and the extraction efficiency of $\mathbf{3}$ significantly increased (Table 1).

In conclusion, the results show that the addition of modifiers can improve extractive performance for the three coumarins. Ethanol proved to be the best of the modifiers tested. These solubility data are essential for the systematic application of SFE- $\mathrm{CO}_{2}$ extraction of coumarins from plant sources.

\section{Acknowledgements}

The authors wish to express their gratitude to Dr. J. C. Ou, National Research Institute of Chinese Medicine, Taipei, Taiwan, for his valuable instruction of the SFE technique. The fruit peel from $C$. maxima (shaddock) used in these experiments was kindly provided by Dr. C. T. Chen, Hwa-Lien District Agricultural Improvement Station, Hwa-Lien, Taiwan.

Table 1. Extraction efficiency for coumarins 1-3 from the fruit peel of Citrus maxima by supercritical fluid extraction with carbon dioxide in the presence or absence of modifiers

\begin{tabular}{|c|c|c|c|c|c|c|c|}
\hline \multirow[b]{3}{*}{ SFE conditions } & \multirow[b]{3}{*}{ Modifier } & \multicolumn{6}{|c|}{ Content $(\mathrm{mg} / \mathrm{g})^{\mathrm{a}}$ and extraction efficiency $(\%)^{\mathrm{b}}$} \\
\hline & & \multicolumn{2}{|c|}{ Imperatorin (1) } & \multicolumn{2}{|c|}{ Meranzin (2) } & \multicolumn{2}{|c|}{ Meranzin hydrate (3) } \\
\hline & & SFE extract & Residue & SFE extract & Residue & SFE extract & Residue \\
\hline $27.6 \mathrm{MPa}, 40^{\circ} \mathrm{C}$ & None & $1.00^{\operatorname{def}}(75)$ & n.d. ${ }^{c}$ & $1.71^{d}(65)$ & $0.73^{\operatorname{deg}}$ & $0.15^{f}(10)$ & $0.94^{\mathrm{de}}$ \\
\hline $27.6 \mathrm{MPa}, 50^{\circ} \mathrm{C}$ & None & $1.12^{\mathrm{deg}}(84)$ & n.d. & $2.00^{d}(76)$ & $0.71^{\mathrm{de}}$ & $0.27^{f}(18)$ & $0.85^{\text {de }}$ \\
\hline $34.5 \mathrm{MPa}, 40^{\circ} \mathrm{C}$ & None & $0.92^{\text {ef }}(68)$ & n.d. & $1.61^{d}(61)$ & $1.12^{\mathrm{g}}$ & $0.27^{f}(18)$ & $1.32^{\mathrm{g}}$ \\
\hline $34.5 \mathrm{MPa}, 50^{\circ} \mathrm{C}$ & None & $0.84^{f}(63)$ & n.d. & $1.94^{d}(74)$ & $0.89^{d g}$ & $0.18^{f}(12)$ & $0.50^{\text {ef }}$ \\
\hline $27.6 \mathrm{MPa}, 50^{\circ} \mathrm{C}$ & $n$-Hexane & $1.18^{\mathrm{dg}}(88)$ & n.d. & $1.88^{d}(71)$ & $0.58^{\text {de }}$ & $0.52^{\mathrm{e}}(35)$ & $1.05^{\mathrm{dg}}$ \\
\hline $27.6 \mathrm{MPa}, 50^{\circ} \mathrm{C}$ & Acetone & $1.09^{\operatorname{deg}}(81)$ & n.d. & $2.04^{\mathrm{d}}(78)$ & $0.68^{\text {de }}$ & $0.65^{d}(44)$ & $0.77^{\text {ef }}$ \\
\hline $27.6 \mathrm{MPa}, 50^{\circ} \mathrm{C}$ & Ethanol & $1.28^{g}(95)$ & n.d. & $2.54^{\mathrm{g}}(97)$ & $0.48^{\mathrm{e}}$ & $1.20^{\mathrm{g}}(81)$ & $0.49^{e}$ \\
\hline
\end{tabular}

a Data are expressed as the mean content. Values bearing the same lower case letters in the same column are not significantly different $(p<0.05)$ according to Duncan's multiple range tests $(n=3)$.

$b$ Extraction efficiency (shown in parentheses) is the ratio of coumarin extracted by $\mathrm{SFE}^{\mathrm{C}} \mathrm{CO}_{2}$ to that extracted by acetone (control) $\times 100 \%$.

${ }^{c}$ n.d. = none detected, below detection limit.

\section{REFERENCES}

Ashraf-Khorassani M, Gidanian S, Yamini Y. 1995. Effect of pressure, temperature, modifier, modifier concentration and sample matrix on the supercritical fluid extraction efficiency of different phenolic compounds. J Chromatogr Sci 33: 658-662.

Averbeck D. 1989. Recent advances in psoralen phototoxicity mechanism. Photochem Photobiol 50: 859-882.

Brogle H. 1982. $\mathrm{CO}_{2}$ as a solvent: its properties and applications. Chem Industry 11: 385-390.
Chen IS, Chang CT, Sheenm WS, Teng CM, Tsai IL, Duh CY, Ko FN. 1996. Coumarins and anti-platelet aggregation constituents from Formosan Peucedanum japonicum. Phytochemistry 41: 525-530.

Chiou WF, Huang YL, Chen CF, Chen CC. 2001. Vasorelaxing effect of coumarins from Cnidium monnieri on rabbit corpus cavernosum. Planta Med 67: 282-284.

Choi YE, Kim J, Noh MJ, Choi ES, Yoo KP. 1998. Effect of functional groups on the solubilities of coumarin 
derivatives in supercritical carbon dioxide. Chromatographia 47: 93-97.

Colombain M, Goll V, Muyard F, Girard C, Bevalot F, Richert L. 2001. A bioassay using the human hepatoblastoma cell line HepG2 for detecting phototoxicity of furocoumarins. Planta Med 67: 644-646.

Hanson M. 1994. Selectivity changes towards steroids in packed column supercritical fluid chromatography (SFEC) induced by temperature and pressure variation. Chromatographia 39: 431-437.

Hills JW, Hill HH. 1993. Carbon dioxide supercritical fluid extraction with a reactive solvent modifier for the determination of polycylic aromatic hydrocarbons. J Chromatogr Sci 31: 6-12.

Hitotsuyanagi $\mathrm{Y}$, Kojima $\mathrm{H}$, Ikuta $\mathrm{H}$, Takeya $\mathrm{K}$, Itokawa $\mathrm{H}$. 1996. Identification and structure-activity relationship studies of osthol, a cytotoxic principle from Cnidium monnieri. Bioorg Med Chem Lett 6: 1791-1794.

Kumar V, Bulumulla HNK, Wimalasiri WR, Reisch J. 1994. Coumarins and an indole alkaloid from Pamburus missionis. Phytochemistry 36: 879-881.
Kwon YS, Kobayashi A, Kajiyama SI, Kawazu K, Kanzaki H, Kim CM. 1997. Antimicrobial constituents of Angelica dahurica roots. Phytochemistry 44: 887889.

Larson KA, King ML. 1986. Evaluation of supercritical fluid extraction in the pharmaceutical industry. Biotechnol Prog 2: 73-82.

Liao CY. 2002. Establish stable clones of lamivudine resistant HBV mutants and study the anti-viral effects of herbal drugs. Masters thesis. National Yang-Ming University Institute of Pharmacology, Taipei, Taiwan.

Sanagi MM, Ahmed UK. 1993. Application of supercritical fluid extraction and chromatography to the analysis of turmeric. J Chromatogr Sci 31: 20-25.

Williams DF. 1981. Extraction with supercritical gases. Chem Eng Sci 36: 1769-1788.

Yamahara J, Kozuka M, Sawada T, Fujimura $H_{4}$ Nakano K, Tomimatsu T, Nohara T. 1985. Biologically active principles of crude drugs. Anti-allergic principles in 'Cnidii monnieri'. Chem Pharm Bull 33: 16761680. 